\title{
Heidelberg Phoneme Discrimination Test (HLAD): Normative Data for Children of the Third Grade and Correlation with Spelling Ability
}

\author{
M. Brunner C. Baeumer S. Dockter F. Feldhusen P. Plinkert U. Proeschel
}

Phoniatrie und Pädaudiologie, Universitäts-Hals-Nasen-Ohrenklinik Heidelberg, Heidelberg, Germany

\section{Key Words}

Heidelberg Phoneme Discrimination Test (HLAD) •

Phoneme discrimination • Phoneme analysis • Writing capacity

\begin{abstract}
Objective: The Heidelberg Phoneme Discrimination Test (HLAD), developed and standardized in 1998, is widely used in the differential diagnosis of dyslexia. Normative data have only been available for children of the 2 nd and 4 th grades, while norms for the 3rd grade are still missing. Patients and Methods: We assessed three HLAD subtests [auditory phoneme discrimination, kinesthetic phoneme discrimination (repeating minimal pairs) and phoneme analysis] in 140 children of the 3rd grade from eight elementary schools. Writing capacity was tested via DRT3. Results: Comparing children of the $2 \mathrm{nd}$, 3rd and 4 th grades, we found a continuing increase in phoneme discrimination capacity with age. This increase was especially evident for the task of auditory comparison. For the 3rd grade, the correlation between HLAD and writing test (qualitative analysis) was 0.55 , and 0.36 between HLAD and writing (quantitative analysis). The correlation with writing tasks was highest in the 2 nd grade. Conclusion: The steady increase in phoneme discrimination capacity from the 2 nd to 4 th grade may indicate maturation and learning effects at least until the age of 10 years.
\end{abstract}

Copyright $\odot 2008$ S. Karger AG, Basel

\section{KARGER}

Fax +4161306 1234 E-Mail karger@karger.ch www.karger.com
(C) 2008 S. Karger AG, Base

1021-7762/08/0603-0157\$24.50/0

Accessible online at:

www.karger.com/fpl

\section{Introduction}

It is common knowledge in dyslexia research that there is not only one but several factors responsible for the difficulties concerning the acquisition of reading and writing skills in dyslexic children. These are social, academic, and familial factors as well as constitutional and cognitive aspects. One of the main risk factors relates to difficulties in speech and language development and speech perception [1-3]. Research into phonological processing and phoneme discrimination is getting more and more in the main focus of interest [4-9].

Impairment in phonological processing can be identified at different levels of processing: at the level of auditory analysis and discrimination, at the level of phonological temporary storage and/or at the level of transforming the phonological information into articulatory processing. Recent neuropsychological studies show a close relationship between phoneme discrimination ability and dyslexia [3]. It has also been shown that children with dyslexic parents are at higher risk for developing an impairment of phoneme discrimination [10]. Clinical experience revealed that many dyslexic children have pronounced difficulties in discrimination and correct articulation of similar sounds, in spite of normal hearing.

In view of the therapeutic options for these children a clear diagnosis of the impairment in phoneme discrimi-

Dr. Dipl. Psych. Monika Brunner

Universitäts-Hals-Nasen-Ohrenklinik Heidelberg, Phoniatrie und Pädaudiologie

Im Neuenheimer Feld 400, DE-69120 Heidelberg (Germany)

Tel. +49 6221567 238, Fax +496221 565732

E-Mail monika_brunner@med.uni-heidelberg.de 
nation and articulation is indispensable. Furthermore, it is important to distinguish this impairment from difficulties concerning the knowledge and use of rules in writing and reading. For this purpose standardized psychometric methods are used, such as the Heidelberg Phoneme Discrimination Test (HLAD) developed by Brunner et al. [11] and Dierks et al. [12]. This test is widely used in the diagnosis of auditory perception impairment and dyslexia in German-speaking countries. However, normative data are only available for the 2 nd and the 4 th grades.

In the HLAD, there are three factor scores that assess the child's auditory perception: phoneme discrimination is tested in part la as an auditory comparison, in part $1 \mathrm{~b}$ as kinesthetic repetition. Part 2 tests metalinguistic skills on the basis of the ability to analyze consonant clusters, especially voiced and voiceless stop sounds at the beginning of a word. The HLAD is available with recording on a sound storage medium, and analysis of the data is computerized.

To test auditory comparison, children are presented 15 pairs of words and 9 pairs of syllables with a different mode of articulation but a similar position of articulation (e.g. /Seide-Seite/, /dra-tra/). Additionally, there are 8 pairs of words and one pair of syllables presented with a similar mode of articulation but a different position (e.g. /Kragen-tragen/). The children's task is to judge whether the pairs sound equal or not. The number of correct words and syllables is registered (HLAD; comparison). For analyzing kinesthetic repetition, the children have to repeat the pairs of words and syllables directly after the comparison task (equal or not equal). The number of correct repetitions is registered (HLAD; repetition). To evaluate phoneme discrimination ability, the children have to specify the first two consonants of 12 words beginning with voiced or voiceless stop sounds. The number of correctly analyzed consonants is registered (HLAD; analysis of word-initial phonemes).

The aim of the investigation was to establish norms for the 3rd grade. Here, dyslexia often appears for the first time when writing untrained dictations. Therefore, standardized evaluation is extremely important. Additionally, writing ability was also investigated. We did not investigate correlation with word reading, as we found in our longitudinal study [13] that language and speech processing variables differentially influence reading and spelling. There was a significant correlation only between speech sound perception and spelling, but not word reading.

\section{Subjects and Methods}

\section{Subjects}

Children of the 3rd grade from eight primary schools around Heidelberg, Germany were investigated. Participation in the study was only possible with the parents' permission. In total, 143 children, aged $7 ; 7$ to $10 ; 6$ (mean 9;1) years, were investigated. Because of hearing impairment due to middle ear ventilation 3 children were excluded from the study. We evaluated the results of 70 boys and 70 girls; 39 children grew up in a multilingual environment.

\section{Methods}

Children of each school were examined individually at the TNE-Heidelberg University Clinic (Phoniatrie und Pädaudiologie). Otoscopy and audiometric diagnostics were made, and phoneme discrimination was examined with the HLAD test, which was part of an extensive test battery. Each assessment lasted $3 \mathrm{~h}$, with breaks in between. One month later, the writing ability of the children was examined in a group session using the German Orthography Test (DRT3) [14] during lessons.

Statistical analysis was done with the computer program SPSS 11.5.1 for Windows.

\section{Results}

For children of the 3rd grade, the mean of the raw score was 21 of 25 items for auditory phoneme discrimination, 17.3 of 25 items for kinesthetic phoneme discrimination, and 9.6 of 12 items for analysis of initial phonemes (table 1). Comparing the means of the 3rd grade to the means of the 2 nd and 4 th grades for auditory phoneme discrimination, there is a continuous increase from the 2 nd up to the 4 th grade for correctly analyzed items. For kinesthetic phoneme discrimination and the analysis of initial phonemes, the results show an increase from the 2nd to the 3 rd grade but not from the 3 rd to the 4 th grade (table 2).

For the determination of normative values, percent ranges were computed for the raw scores of the HLAD, respectively. As pointed out, averages ranged between 15 and $85 \%$. Raw scores according to the average range of the percent ranges, respectively, can be seen in table 3. For children of the 3rd grade, the average distribution of raw scores (RW) was RW $=18-24$ for auditory phoneme discrimination (2nd grade: $\mathrm{RW}=17-22$; 4 th grade: $\mathrm{RW}=$ 20-24), for kinesthetic phoneme discrimination RW = $12-22$ (2nd grade: $\mathrm{RW}=8-17$, 4th grade: $\mathrm{RW}=14-21$ ), and for analysis of initial phonemes RW $=7-11$ (2nd grade: $\mathrm{RW}=4-10$, 4th grade: $\mathrm{RW}=7-11$ ).

Correlation coefficients between the total score and the subtest scores of the HLAD and the DRT3 total score 
Table 1. Distribution of raw scores

\begin{tabular}{lrllll}
\hline & \multicolumn{2}{l}{ HLAD } & & $\begin{array}{l}\text { DRT3 } \\
\text { total }\end{array}$ \\
\cline { 2 - 5 } & total & $\begin{array}{l}\text { auditory } \\
\text { comparison }\end{array}$ & $\begin{array}{l}\text { kinesthetic } \\
\text { repetition }\end{array}$ & $\begin{array}{l}\text { analysis of word- } \\
\text { initial phonemes }\end{array}$ & \\
\hline Mean & 47.6 & 21 & 17.3 & 9.6 & 19.7 \\
SD & 8.9 & 3.0 & 4.7 & 6.2 & 10.1 \\
\hline
\end{tabular}

Table 2. Comparison (2nd, 3rd, 4 th grades) of the means of correctly analyzed items (data for 2 nd and 4 th grades from Dierks et al. [12])

\begin{tabular}{|c|c|c|c|}
\hline & $\begin{array}{l}\text { 2nd } \\
\text { grade }\end{array}$ & $\begin{array}{l}\text { 3rd } \\
\text { grade }^{1}\end{array}$ & $\begin{array}{l}4 \text { th } \\
\text { grade }\end{array}$ \\
\hline Auditory comparison (total 25 items) & 19.4 & 21 & 22 \\
\hline Kinesthetic repetition (total 25 items) & 12.2 & 17.3 & 17.3 \\
\hline $\begin{array}{l}\text { Analysis of word-initial phonemes } \\
\text { (total } 12 \text { items) }\end{array}$ & 6.7 & 9.6 & 9.3 \\
\hline HLAD total & 38.3 & 47.6 & 48.6 \\
\hline
\end{tabular}

${ }^{1}$ See table 1.

Table 3. Distribution of the percent ranges (PR) of the HLAD raw scores: comparison of the $2 \mathrm{nd}$, $3 \mathrm{rd}$, and 4 th grades

\begin{tabular}{|c|c|c|c|c|c|c|c|c|c|}
\hline \multirow[t]{2}{*}{ Raw scores } & \multicolumn{3}{|c|}{ Auditory comparison, $\mathrm{PR}$} & \multicolumn{3}{|c|}{ Kinesthetic repetition, PR } & \multicolumn{3}{|c|}{ Analysis of word-initial phonemes, PR } \\
\hline & 2nd grade & 3rd grade & 4 th grade & 2nd grade & 3rd grade & 4 th grade & 2nd grade & 3rd grade & 4 th grade \\
\hline 0 & & & & & & & 2 & & \\
\hline 1 & & & & 0 & & & 5 & & \\
\hline 2 & & & & 1 & & & 8 & & \\
\hline 3 & & & & 3 & & & 11 & & \\
\hline 4 & & & & 6 & & 1 & 15 & 1 & \\
\hline 5 & & & & 8 & & & 23 & 2 & 3 \\
\hline 6 & & & & 11 & 1 & & 37 & 8 & 9 \\
\hline 7 & & & & 14 & 2 & & 55 & 18 & 17 \\
\hline 8 & & & & 20 & 3 & 3 & 68 & 29 & 28 \\
\hline 9 & & & & 28 & 4 & 5 & 78 & 40 & 41 \\
\hline 10 & & & & 33 & 7 & 7 & 85 & 48 & 57 \\
\hline 11 & 0 & & & 39 & 12 & & 92 & 62 & 74 \\
\hline 12 & 1 & & & 46 & 16 & 10 & 99 & 87 & 91 \\
\hline 13 & & & & 55 & 20 & 13 & & & \\
\hline 14 & 3 & 1 & & 64 & 25 & 18 & & & \\
\hline 15 & 7 & 5 & & 72 & 30 & 26 & & & \\
\hline 16 & 14 & 10 & 1 & 78 & 36 & 33 & & & \\
\hline 17 & 23 & 13 & 3 & 83 & 44 & 41 & & & \\
\hline 18 & 31 & 18 & 8 & 87 & 51 & 52 & & & \\
\hline 19 & 42 & 26 & 14 & 91 & 59 & 62 & & & \\
\hline 20 & 55 & 34 & 21 & 96 & 67 & 70 & & & \\
\hline 21 & 68 & 45 & 31 & 99 & 75 & 81 & & & \\
\hline 22 & 80 & 56 & 43 & & 83 & 90 & & & \\
\hline 23 & 88 & 68 & 59 & & 91 & 95 & & & \\
\hline 24 & 95 & 81 & 76 & & 96 & 99 & & & \\
\hline 25 & 99 & 95 & 92 & & 99 & & & & \\
\hline
\end{tabular}

Figures in italics are PR normal range.

and the DRT3 score of perception errors, respectively, are shown in table 4 . All correlations but one are significant at the 0.01 level. Correlation coefficients $>0.50$ can be seen in correlations of the HLAD with spelling errors of the category 'perception error' (table 4). Comparing the correlations between HLAD and the DRT in the different grades (2nd, 3rd, 4th), it becomes apparent that the highest correlations are for the 2 nd grade (table 5 ). 
Table 4. Correlations of HLAD and DRT3

\begin{tabular}{lll}
\hline & $\begin{array}{l}\text { DRT3 total } \\
\text { (word error) }\end{array}$ & $\begin{array}{l}\text { DRT subscore } \\
\text { 'perception } \\
\text { spelling error' }\end{array}$ \\
\hline $\begin{array}{l}\text { HLAD auditory comparison } \\
\text { HLAD kinesthetic repetition }\end{array}$ & $0.29^{*}$ & $0.51^{*}$ \\
$\begin{array}{l}\text { HLAD analysis of word-initial } \\
\text { phonemes }\end{array}$ & $0.41^{*}$ & $0.52^{*}$ \\
\hline HLAD total & $0.27^{*}$ & $0.42^{*}$ \\
\hline$* \mathrm{p}=0.05$. & $0.36^{*}$ & $0.55^{*}$ \\
\hline
\end{tabular}

Table 5. Correlations of HLAD and writing ability in the 2nd, $3 \mathrm{rd}$, and 4 th grades (data for 2 nd and 4 th grades from Dierks et al. [12])

\begin{tabular}{llll}
\hline & \multicolumn{3}{l}{ Writing ability } \\
\cline { 2 - 4 } & $\begin{array}{l}\text { 2nd } \\
\text { grade }\end{array}$ & $\begin{array}{l}\text { 3rd } \\
\text { grade }\end{array}$ & $\begin{array}{l}4 \text { th } \\
\text { grade }\end{array}$ \\
\hline $\begin{array}{llll}\text { HLAD auditory comparison } \\
\text { HLAD kinesthetic repetition }\end{array}$ & $0.44^{* * *}$ & $0.29^{* *}$ & $0.21^{* *}$ \\
$\begin{array}{l}\text { HLAD analysis of word-initial } \\
\text { phonemes }\end{array}$ & $0.47^{* * *}$ & $0.41^{* *}$ & $0.31^{* * *}$ \\
\hline HLAD total & $0.49^{* * *}$ & $0.27^{* *}$ & $0.19^{*}$ \\
\hline
\end{tabular}

${ }^{*} \mathrm{p}=0.05 ;{ }^{* *} \mathrm{p}=0.01 ;{ }^{* *} \mathrm{p}<0.01$

\section{Discussion}

Comparing the raw scores of the HLAD for the 2nd, $3 \mathrm{rd}$, and 4 th grades and comparing the distribution of normative values, there is a continual increase in auditory phoneme discrimination with higher grades and with age. It seems that the ability to accomplish auditory discrimination between similar phonemes is increasing continually. Most of the consonants that had to be discriminated differed in the voiced/voiceless dimension. Psychoacoustically, the consonants differed in terms of formant transients and time analyses taking place in milliseconds [3]. Therefore, one has to assume that in normally developing children there are maturation and learning effects for auditory phoneme discrimination at least until the age of 10 . However, as the size of the sample is rather small, we interpret this data as preliminary. Further studies should confirm these results.
Different results appeared for kinesthetic phoneme discrimination and the analysis of word-initial phonemes. A clear increase was found from the 2 nd to the 3 rd grade, but not from the 3 rd to the 4 th grade. Here, there was only minimal or no increase in the ability to analyze word-initial phonemes. On closer inspection, concerning auditory phoneme discrimination, one can see additionally that the spectrum of the norms is quite wide for the 2nd and 3rd grades, getting smaller only at the 4 th grade. This means that the spectrum of ability for auditory phoneme discrimination is spread widely in the children of the 2 nd and 3 rd grades, while children of the 4 th grade seem to be more on the same level concerning auditory phoneme discrimination.

Results for the analysis of word-initial phonemes showed that children of the 2 nd grade are already able to achieve the same maximum values as children of the 4th grade. In total, it seems that the ability to analyze clusters of consonants at the beginning of a word is not yet fully developed in the 2nd grade, and normally completed at the end of the 3rd grade. Windsor [15] found similar results: it is important to analyze letter per letter at the beginning of the acquisition of writing skills. Later, however, analysis of connected word units such as syllables and morphemes gains influence.

Concerning the relationship between the ability of phoneme discrimination and spelling, the highest values were found for the correlation with the category 'perception errors' in the Diagnostic Writing Test (DRT) (table 4). It seems that problems of the auditory perception of voiced and voiceless consonants have an influence on errors of the phoneme-grapheme classification of these consonants. Unfortunately, corresponding data for the 2nd and 4th grades were not available.

Moderate correlations were found in the qualitative analysis of writing tests (category of perception errors) for the 3rd grade. Correlations of a similar order were shown by Schulte-Körne [3] between active discrimination of /da-ga/ and the writing ability of children of the 2nd grade. Table 5 shows that the correlation coefficients for the HLAD and the writing tests decrease the higher the grade or age, respectively. The highest correlation coefficients were shown in the 2nd grade. Accordingly, Möhring et al. [16] specified the HLAD as a significant predictor concerning the spelling ability of children of the 2nd grade. Graf [17] and Walter [18] showed that phonological processing and auditory phoneme discrimination ability are a meaningful factor especially in the 2 nd grade. It is of significant impact at the beginning of learning the written language because accurate phoneme- 
grapheme correspondence is most important at this age. In the higher grades other cognitive abilities seem to get more important for correct writing, like knowledge of rules and learning strategies. It is not yet clear whether this is also true for dyslexic children, or whether the influence of inadequate phoneme discrimination continues to be visible in these children to the higher grades. Schulte-Körne [3] reported a significant difference in phoneme discrimination of /d-b/ between dyslexic children and normally developing children of the 5th and 6th grades. Our own clinical experience also suggests that dyslexic children show more errors concerning inadequate auditory perception up to higher school grades. On the basis of this study, however, we think that the test is best suited as a diagnostic tool for dyslexia in the lower grades of primary school.

\section{References}

1 Klicpera C, Gasteiger-Klicpera B: Psychologie der Lese- und Schreibschwierigkeiten. Weinheim, Beltz, 1995.

2 de Montfort Supple M: Dyslexia: oral and written language disorder. Folia Phoniatr Logop 2000;52:7-13.

3 Schulte-Körne G: Lese-Rechtschreibstörung und Sprachwahrnehmung. Münster, Waxmann, 2001.

4 Bradley L, Bryant P: Categorizing sounds and learning to read: a causal connection. Nature 1983;301:419-421.

5 Bruck M, Waters G: Effects of reading skill on component spelling skills. Appl Psycholinguist 1990;11:425-437.

6 Manis FR, Szeszulski PA, Holt LK, Graves K: Variation in component word recognition and spelling skills among dyslexic children and normal readers; in Carr TH, Levy BA (eds): Reading and Its Development: Component Skills Approaches. San Diego, Academic Press, 1990, pp 207-259.

7 Hulme C, Snowling MJ: Deficits in output phonology: an explanation of reading failure. Cogn Neuropsychol 1992;9:47-72.
Stanovich KE, Siegel L: Phenotype performance profile of children with reading disabilities: a regression-based test of the phonological-core variable-difference model. J Educ Psychol 1994;86:24-53.

-9 Tallal P, Miller S, Bedi G, Byma G, Wang X, Nagarajan S, Schreiner C, Jenkins WM, Merzenich MM: Language comprehension in language learning disabled children improved with acoustically modified speech Science 1996;271:81-84.

10 Pihka E, Leppänen PHT, Eklund KM, Cheour M, Guttom TK, Lyytinen H: Cortex responses of infants with and without dyslexia. I. Age effects. Neuroreport 1999;10: 901-905.

11 Brunner M, Seibert A, Dierks A, Körkel B: Heidelberger Lautdifferenzierungstest (HLAD). Wertingen, Westra Elektroakustik, 1998.

12 Dierks A, Seibert A, Brunner M, Körkel B, Haffner J, Strehlow U, Parzer P, Resch F: Testkonstruktion, -analyse und Erprobung des Heidelberger Lautdifferenzierungstests zur auditiv-kinästhetischen Wahrnehmungstrennschärfe. Z Kinder Jugendpsychiatr Psychother 1999;27:29-36.
13 Troost J, Brunner M, Pröschel U: Validität des Heidelberger Vorschulscreenings zur auditiv-kinästhetischen Wahrnehmung und Sprachverarbeitung. Diagnostica 2004;50: 193-201.

14 Müller R: Diagnostischer Rechtschreibtest für 3. Klassen. Weinheim, Beltz, 1997.

15 Windsor J: The role of phonological opacity in reading achievement. J Speech Lang Hear Res 2000;43:50-61.

16 Möhring L, Schöler H, Brunner M, Pröschel U: Zur Diagnostik struktureller Defizite bei Lese-Rechtschreib-Störungen in der klinischen Arbeit: Beziehungen zwischen verschiedenen Leistungsindikatoren. Laryngorhinootologie 2003;82:83-91.

17 Graf E: Lese-Rechtschreibschwäche: ein prozessanalytischer Ansatz. Bern, Lang, 1994.

18 Walter J: Förderung bei Lese-Rechtschreibschwäche: Grundlagenforschung, methodische Konsequenzen, Praxisbeispiele und mediendidaktische Anregungen auf der Basis empirischer Forschungsmethoden. Göttingen, Hogrefe, 1996. 